\title{
Troponin Measurement
}

National Cancer Institute

\section{Source}

National Cancer Institute. Troponin Measurement. NCI Thesaurus. Code C111327.

The determination of the amount of total troponin present in a sample. 